\title{
White-coat hypertension and masked hypertension: an update
}

\author{
Nathan Artom, ${ }^{1}$ Francesco Salvo, ${ }^{2}$ Francesca Camardella ${ }^{2}$ \\ ${ }^{1}$ Clinic of Internal Medicine 1, Department of Internal Medicine, University of Genoa School of Medicine, IRCCS AOU San \\ Martino-IST, Genoa; ${ }^{2}$ Division of Internal Medicine, Poveri Infermi Hospital, Ceva (CN), Italy
}

\begin{abstract}
White coat hypertension and masked hypertension are two conditions with a controversial role in the beginning and the progression of the cardiovascular disease. We focused our attention on the definition, the epidemiology, the pathophysiology and the clinical consequences of these two conditions, with an attention also on the management. This review was based on the papers found on PubMed and MEDLINE up to August 2015. The search terms used were white coat hypertension, masked hypertension in combination with epidemiology, management and pathophysiology.
\end{abstract}

\section{Introduction}

The precise quantification of blood pressure (BP) is an essential step to reach the largest number of correct diagnosis of arterial hypertension (AH) and consequently to optimize the anti-hypertensive therapy. Since the invention of the first sphygmomanometer in 1896, Riva-Rocci observed the inaccuracy of that method for a correct BP determination: ${ }^{1}$ the simple appearance of a doctor was accompanied by an immediate rise in BP in some patients. Years later Pickering called this phenomenon white coat hypertension (WCHT). ${ }^{2}$ The introduction of fully-automated BP measurement during the $24 \mathrm{~h}$ (ambulatory blood pressure monitoring, ABPM) allowed to observe the entire

\footnotetext{
Correspondence: Nathan Artom, Clinic of Internal Medicine 1, Department of Internal Medicine, University of Genoa School of Medicine, IRCCS AOU San Martino - IST, viale Benedetto XV 6, 16132 Genoa, Italy.

Tel.: +39.348.0025220. E-mail: nat.artom@hotmail.it

Key words: White coat hypertension; masked hypertension.

Contributions: NA, FS contributed equally as first authors to this work.

Conflict of interest: the authors declare no potential conflict of interest.

Received for publication: 13 September 2015.

Revision received: 30 September 2015.

Accepted for publication: 2 October 2015.

This work is licensed under a Creative Commons Attribution NonCommercial 4.0 License (CC BY-NC 4.0).

(C) Copyright N. Artom et al., 2016

Licensee PAGEPress, Italy

Italian Journal of Medicine 2016; 10:96-102

doi:10.4081/itjm.2015.662
}

circadian BP profile, highlighting how BP could be normal in physician office and elevated at home, especially during the nocturnal period. ${ }^{3}$ This last observation was named masked hypertension (MHT). ${ }^{4}$

WCHT is defined as office BP persistently $\geq 140$ $\mathrm{mmHg}$ systolic, $\geq 90 \mathrm{mmHG}$ diastolic, or both, whereas out-of-office BP is within normal $(<130 / 80$ mmHg for 24-h mean BP, or $<135 / 85$ mmHG for home BP). ${ }^{5-7}$ Medical environment triggers this alarm reaction, ${ }^{8}$ through the hyperactivation of sympathetic nervous system. ${ }^{9}$ It peaked 2-4 min after the start of the visit and continued throughout the duration of the physician's visit. ${ }^{10}$ For this reason, international guidelines recommended to record at least two ABPM to confirm the diagnosis of WCHT and to determine the possible development of sustained hypertension. ${ }^{11}$ Further WCHT can be divided into true $\mathrm{WCH}$, when both home BP values and ABPM values are normal, and partial WCHT, when only one of these out-of-office measurements is normal. ${ }^{5}$

If WCHT can determinate an overdiagnosis of $\mathrm{AH}$, on the other hand some subjects present normal office $\mathrm{BP}$ values in contrast to pathological 24-h BP profile on ABPM or altered home BP. This reverse white-coat effect or MHT ${ }^{12,13}$ is related to a worse cardiovascular (CV) prognosis ${ }^{14}$ and also to the development of a target organ damage (TOD) comparable to sustained hypertension patients ${ }^{15}$ (Table 1). Both WCHT and MHT are examples of how the correct evaluation of BP profile is a difficult challenge and how their better knowledge can lead to a more precise diagnosis and consequently to a proper treatment of AH.

\section{Epidemiology}

The prevalence of WCHT and MHT is not completely clear. AS a confounding factor several studies showed different values for normal BP. Regarding 
WCHT, Pickering and co-workers in 1988 reported a prevalence of 21 in 292 patients $(7.2 \%)$; $^{2}$ in subsequent years other studies showed various frequencies, ranging from $15.1 \%$ in the Finn Home Study, which involved 1540 untreated subjects aged 44 to 75 years, ${ }^{16}$ to $15-45 \%$ of the Pressioni Arteriose Monitorate E Loro Associazioni (PAMELA) study, a Mancia's large population trial which assessed the $\mathrm{CV}$ and all-cause mortality over 16 years in 2051 patients aged 25-74 years. ${ }^{12}$ Lately, the 2014 position paper on ABPM estimated a WCHT prevalence of $15-30 \%$. ${ }^{7}$

Among subjects older than 80 years, the Hypertension in the Very Elderly Trial (HYVET) showed a $50 \%$ prevalence of the WCHT. ${ }^{17}$ However it is well known that the office BP and mean ambulatory BP difference increases with age and it is unlikely that the definition of WCHT is appropriate over 80 years. Conen and colleagues ${ }^{18}$ recently demonstrated that the prevalence of WCHT exponentially increased from $2.2 \%$ to $19.5 \%$ from those aged 18 to 30 years to those aged $\geq 70$ years. WCHT is also more prevalent among female gender. ${ }^{19}$ Otherwise, smoking habit seems to be a protective factor. ${ }^{20}$

The exact prevalence of MHT was achieved with the introduction of ABPM that showed a diagnostic sensitivity higher than home BP monitoring (HBPM). ${ }^{21}$ Indeed analysis from PAMELA reported a prevalence of $9 \% ; 22$ other studies reported frequencies ranging from $10.2 \%{ }^{23}$ to $23 \%,{ }^{24}$ reaching even $48 \%{ }^{25}$ It might be fair to say that since the WCHT is more common in the elderly, consequently MHT should gradually decline with age. ${ }^{26,27}$ However, the increasing prevalence of reduced nocturnal BP dipping among older patients, ${ }^{28}$ could alter this assertion. The prevalence is around $10 \%$ among children and young adults. ${ }^{29}$ Overall MHT is more prevalent in male gender and past smokers. ${ }^{24}$ Other risk factors are high normal office BP, the overweight and a higher education level..$^{30}$ Also, it was showed how middle-age athletes have a higher prevalence of MHT31 (Table 2).

\section{Pathophysiology}

The physiological mechanisms that underlie WCHT and MHT are quite different. Utilizing microneurography, a methodology which measures the muscles and skin sympathetic nerve traffic, Grassi and co-workers demonstrated that subjects with WCHT presented pronounced activation of skin nerves and associated sympathetic inhibition of muscle nervetraffic when physicians either took BP measurements or were present during these measurements. ${ }^{32} \mathrm{Re}$ searchers indicate that this response is similar to a defense reaction that has been demonstrated in animal models when they react to emotional stressors and is largely dependent by diencephalic areas. ${ }^{33}$

The partial inhibition of these responses could underlie the reduced prevalence of WCHT among tobacco users. ${ }^{34}$ Therefore, emotional factors such as anxiety or stress may be responsible for this microneurographic response and the origin of WCHT. ${ }^{35}$ Patients with WCHT showed higher levels of anxiety compared with both normotensive individuals and patients with sustained hypertension. ${ }^{36}$ However, research has also showed that patients who are prone to WCHT do not hyperreact to all types of emotional stimuli. Instead, they only react to emotional stimuli that have been associated with a physician's office or the physician. ${ }^{37}$ This situational anxiety was further investigated in a study conducted by Ogedegbe and co-workers: patients who experience WCHT presented high anxiety at physicians' offices as a result of previous negative or painful experiences with the medical office or physician. ${ }^{38}$ Results from this study also indicated that patients who had expectations of high BP when being measured experienced elevated

Table 1. Comparison between different blood pressure (BP) measurement methods among BP profiles.

\begin{tabular}{lccc}
\hline & Office BP & HBPM & ABPM \\
\hline True normotension & Normal & Normal & Normal \\
\hline Sustained hypertension & Elevated & Elevated & Elevated \\
\hline White-coat hypertension & Elevated & Normal & Normal \\
\hline Masked hypertension & Normal & Elevated & Elevated
\end{tabular}

BP, blood pressure; HBPM, home blood pressure monitoring; ABPM, ambulatory blood pressure monitoring.

Table 2. Prevalence of white-coat hypertension and masked hypertension among different studies.

\begin{tabular}{lc}
\hline & Prevalence (\%) \\
\hline White-coat hypertension & $2.2-50$ \\
\hline Masked hypertension & $9-48$ \\
\hline
\end{tabular}


BP. This is caused by an anxiety related to their expectations, rather than being caused by a persistent trait anxiety of the patients. ${ }^{39}$

WCHT seems to be a condition with an impaired baroreflex of vagal, but not of the sympathetic, $\mathrm{CV}$ system with a consequent hyperadrenergic state similar to that detected in subjects with sustained hypertension. ${ }^{40}$

About MHT, it is better to focus the attention not only on an etiologic mechanism but also on the methodological topic: as we said before, with the introduction of HBPM first and after the ABPM fullyautomated devices, it was possible to analyze the entire circadian BP profile far from medical environment. For example, Mann et al. reported that smoking habit elevates the mean diurnal systolic BP despite a similar clinic BP between smokers and non-smokers, ${ }^{41}$ leading to an undertreatment. ${ }^{42}$ Other factors associated with high diurnal BP are alcohol intake ${ }^{43}$ and physical activity. ${ }^{44} \mathrm{ABPM}$ is usually performed during a normal day, including the working period. As showed by Pieper and colleagues ${ }^{45}$ working environment can significantly change BP, both in normotensive and hypertensive subjects. ${ }^{46,47}$ Also during the night period some factors interfere with the entire circadian BP profile. Aydin and coleagues ${ }^{48}$ demonstrated that subjects exposed to a higher noise at night showed a higher morning BP. A similar relief was found with sleep deprivation. ${ }^{49}$

The possible role in MHT of sympathetic nervous system alteration leading to an isolated nocturnal hypertension was present more frequently in particular groups of patients, such as diabetics ${ }^{50}$ (Table 3 ).

\section{Clinical consequences}

The prognostic value of WCHT is still under debate. If National Institute for Health and Clinical Excellence (NICE) guidelines did not stress this topic, ${ }^{51}$ the European Society of Cardiology/European Society of Hypertension (ESC/ESH) guidelines ${ }^{5}$ underline the importance of subjects with WCHT when compared

Table 3. Conditions associated with white-coat hypertension and masked hypertension.

\begin{tabular}{lcc}
\hline & WCHT & MHT \\
\hline Predisposing factors & Female gender & Male gender \\
& Non smoking habit & Smoking habit \\
& Anxiety & Overweight \\
Old patient & Night noise \\
& High normal BP \\
& Diabetes mellitus \\
& Young patient \\
\end{tabular}

WCHT, white-coat hypertension; MHT, masked hypertension; BP, blood pressure. to normotensives. Several cross sectional studies investigated the association between WCHT and asymptomatic TOD. The results are conflicting: if some studies showed that subjects with WCHT, when compared to normotensives, had an increased TOD like left ventricular hypertrophy (especially in elderly), ${ }^{52}$ diastolic dysfunction, ${ }^{53,54}$ increased intima-media thickness (IMT) and kidney damage (for example proteinuria), ${ }^{55,56}$ other studies found no associations. ${ }^{57}$ Further, the increased degree of TOD showed in some studies did not have prognostic significance. ${ }^{58,59}$ Longitudinal studies did not clarify these discrepancies. In two large studies, the incidence of CV events was similar in WCHT subjects when compared to normotensive subjects $^{60,61}$ or sustained mild hypertension. ${ }^{62}$ These data were also confirmed by a meta-analysis published in $2007 .{ }^{63}$ However, other data demonstrated that WCHT is not clinically benign. A Danish study, with a ten-year follow-up, demonstrated that WCHT was associated with a significant increase in $\mathrm{CV}$ risk when compared to normotensive subjects. However, this risk was lower with respect to the CV risk of subjects with sustained hypertension. ${ }^{64}$ The PAMELA study showed similar results, with an increase of hard endpoint such as total mortality and $\mathrm{CV}$ mortality in subjects with WCHT when compared with normotensive subjects. However, when subjects with WCHT were divided into two subgroups, those with true WCHT and those with partial WCH, the significance of these outcomes was maintained only in the second subgroup. The PAMELA study also clearly showed that WCHT increased the risk of sustained hypertension. ${ }^{12}$ Several factors could explain the increased CV risk of WCHT subjects. These patients, when compared to normotensive subjects, demonstrated more metabolic risk factors, a higher BP variability, a well-known independent risk factor for $\mathrm{CV}$ events. ${ }^{65}$ Furthermore, when compared to normotensives, WCHT subjects showed home and ambulatory BP measurements in the upper normotensive range. ${ }^{65,66}$

Instead, regarding MHT, recent meta-analysis showed how this phenomenon is undoubtedly associated with a higher left ventricular mass index ${ }^{67}$ and with a greater IMT, ${ }^{68,69}$ when compared with normotensive subject. The alteration in those two indicators in MHT is similar to that observed in sustained hypertension. ${ }^{69}$ In addition, beyond IMT thickening, there was an increased incidence of carotid plaque stenosis. ${ }^{70}$ This is the possible reason for the prognostic overlap between MHT and sustained hypertension. ${ }^{71,72}$ The Masked Hypertension Study also showed that MHT determines during follow-up diastolic dysfunction such as sustained hypertension. ${ }^{73}$ Further, Lurbe and colleagues, in a cohort of 272 subjects aged 6-18 years showed that subjects with MHT $(n=39)$ 
presented a higher risk of sustained hypertension during time, and this risk was higher in male patients. ${ }^{74}$

Although clinic BP is in the normal range in subjects with MHT, optimal values $(<120 / 80 \mathrm{mmHg})$ are related to a lower prevalence of this alteration with a lower presence of $\mathrm{TOD}^{75}$ and also with a lower incidence of MHT during a long follow-up period. ${ }^{76} \mathrm{How}-$ ever, this cut-off value lead to an high false-positive rate. ${ }^{77}$ Home $\mathrm{BP}$ measurement could be useful in the diagnosis and in the prognostic stratification, also for the nocturnal period ${ }^{78}$ but ABPM seems to be the best method to make an accurate diagnosis. ${ }^{79,80}$ In addition, the Ohasama study demonstrated, in a cohort of 843 subjects of the general population who performed ABPM, that the nocturnal BP values were the best predictor of future chronic kidney disease.$^{81}$ In the Japan Morning Surge Home Blood Pressure (J-HOP) Study, Kario et al. developed a more comfortable device with respect to traditional $\mathrm{ABPM}$ device focused on the night time BP values of 02:00, 03:00, 04:00 a.m., which showed in 2562 subjects a strict correlation between nighttime BP values and TOD. ${ }^{82}$ However, traditional ABPM devices remain the gold standard also for the evaluation of the night time period. ${ }^{83}$

In conclusion, both WCHT and MHT increased the risk to produce sustained hypertension and TOD. ${ }^{66}$ However, several data showed a worse prognosis in subjects with MHT: in the Finn Home Study subjects with MHT or sustained hypertension presented a higher TOD when compared to normotensives or subjects with WHT. ${ }^{84,85}$

\section{Management}

When the physician made a diagnosis of WCHT, he should investigate the existence of metabolic risk factors, the presence of TOD, with meticulous follow-up. The first approach is lifestyle interventions. For those with $\mathrm{CV}$ risk factors and TOD, a pharmacological approach could be considered as a first-line treatment. ${ }^{86}$

Interestingly, the European Lacidipine Study on Atherosclerosis (ELSA) recently demonstrated that anti-hypertensive treatments in WCHT subjects reduced office BP similar to subjects with sustained hypertension, whereas it did not have any consistent lowering effect on $24 \mathrm{~h}$, daytime and nighttime BP. ${ }^{87}$ By contrast, subjects with sustained hypertension had both office and ambulatory BP reduction. This is the only available trial in which all the subjects underwent office and ambulatory BP measurements before and at yearly intervals during a 4-year anti-hypertensive treatment period. The ELSA trial did not give information about the eventual protective role of anti-hypertensive treatment in WCHT patients. The results of a large database ${ }^{88}$ and of the Systolic Hypertension (SystEur) trial ${ }^{89}$ showed that in WCHT subjects the pharmacological treatments did not lower the $\mathrm{CV}$ risk. However, these two trials only 1 on-treatment ambulatory BP was available. Furthermore, in the SystEur substudy the number of patients and events was too small to give sufficient statistical power. ${ }^{90}$ Third in the large database there are no ambulatory BP baseline values. ${ }^{89}$ By contrast, a big meta-analysis showed that the treatment of office BP levels resulted in a reduction of $\mathrm{CV}$ events, regardless of the ambulatory and home BP values of the studies subjects..$^{90}$ However, further randomized trial are needed for clarifying the best management of WCHT.

On the other hand, an incorrect diagnosis and treatment of MHT lead clearly to a worse CV prognosis. ${ }^{91}$ Consequently it is fundamental to identify those subjects with a higher risk of MHT, in order to start an adequate therapy and assure an optimal BP control.

Angeli and colleagues proposed a diagnostic algorithm to identify patients with high risk of MHT in order to make ABPM only for those at high risk: subjects with pre-hypertension, smokers, high alcohol consumption, male gender, diabetes, obesity and environmental stress. ${ }^{92}$ The high prevalence of MHT in diabetes, particularly due to an elevated BP during the night period, ${ }^{93}$ with reverse dipping pattern, ${ }^{94}$ can be limited with an adequate chronotherapy: American Diabetes Association (ADA) guidelines suggest to administer at least one anti-hypertensive medication at bedtime. ${ }^{95}$ Further, in the International Database in Ambulatory blood pressure in relation to Cardiovascular Outcomes showed a difficult in BP control in diabetes subjects with MHT, with worst outcomes, so the clinician may pay particular attention in BP control of this group. ${ }^{96}$ Despite the increased adoption of HBPM and clear utility for diagnosis, as demonstrated in obese patients, ${ }^{97} \mathrm{ABPM}$ remain the best method to correctly assess the cardiovascular prognosis also at follow-up. ${ }^{98}$

\section{Conclusions}

WCHT and MHT are two opposite phenomena, which represent an incorrect quantification of the patient's BP profile, leading often to an inappropriate treatment with consequences on $\mathrm{CV}$ prognosis. WCHT is a situation of higher risk when compared to normotensives, caused by an hyperadrenergic state, with a high prevalence which increases with age. By contrast, MHT can be also in young patients an important source of morbidity, mainly determined by an underestimation of BP control during the $24 \mathrm{~h}$.

Both MHT and WCHT are often associated with metabolic risk factor, odds ratio, and the development of sustained hypertension, but MHT seems to be a condition with a worse prognosis. In daily clinical practice the identification and the management of these two conditions, especially through ABPM but 
also with HBPM, is of crucial importance for patient's lifetime $\mathrm{CV}$ risk.

\section{References}

1. Riva-Rocci S. La tecnica della sfigmomanometria. Gazzetta Medica di Torino 1897;48:181-91.

2. Pickering TG, James GD, Boddie C, et al. How common is white coat hypertension? JAMA 1988;259:225-8.

3. Pickering TG, Shimbo D, Haas D. Ambulatory bloodpressure monitoring. N Engl J Med 2006;354:2368-74.

4. Devereux RB, Pickering TG. Ambulatory blood pressure in assessing the cardiac impact and prognosis of hypertension. In: O'Brien E, O' Malley K, eds. Blood pressure measurement. Handbook of hypertension. Vol. 14. Amsterdam: Elsevier; 1991. pp 261-85.

5. Mancia G, Fagard R, Narkiewicz K, et al. 2013 $\mathrm{ESH} / \mathrm{ESC}$ guidelines for the management of arterial hypertension: the Task Force for the Management of Arterial Hypertension of the European Society of Hypertension (ESH) and of the European Society of Cardiology (ESC). Eur Heart J 2013;34:2159-219.

6. O’Brien E, Parati G, Stergiou G, et al. European Society of Hypertension position paper on ambulatory blood pressure monitoring. J Hypertens 2013;31:1731-68.

7. Parati G, Stergiou G, O'Brien E, et al. European Society of Hypertension practice guidelines for ambulatory blood pressure monitoring. J Hypertens 2014;32:1359-66.

8. Pan Y, Cai W, Cheng Q, et al. Association between anxiety and hypertension: a systematic review and metaanalysis of epidemiological studies. Neuropsychiatr Dis Treat 2015;11:1121-30.

9. Grassi G, Turri C, Vailati S, et al. Muscle and skin sympathetic nerve traffic during the "white-coat" effect. Circulation 1999;100:222-5.

10. Mancia G, Bertinieri G, Grassi G, et al. Effects of bloodpressure measurement by the doctor on patient's blood pressure and heart rate. Lancet 1983;2:695-8.

11. O'Brien E, Asmar R, Beilin L, et al. European Society of Hypertension recommendations for conventional, ambulatory and home blood pressure measurement. J Hypertens 2003;21:821-48.

12. Mancia G, Sega R, Bravi C, et al. Ambulatory blood pressure normality: results from the PAMELA study. J Hypertens 1995;13:1377-90.

13. Wing LM, Brown MA, Beilin LJ, et al. Reverse whitecoat hypertension in older hypertensives. J Hypertens 2002;20:639-44.

14. Pierdomenico SD, Cuccurullo F. Prognostic value of white-coat and masked hypertension diagnosed by ambulatory monitoring in initially untreated subjects: an updated meta-analysis. Am J Hypertens 2011;24:52-8.

15. Kotsis V, Stabouli S, Toumanidis S, et al. Target organ damage in "white coat hypertension" and "masked hypertension". Am J Hypertens 2008;21:393-9.

16. Hänninen MR, Niiranen TJ, Puukka PJ, et al. Target organ damage and masked hypertension in the general population: the Finn-Home study. J Hypertens 2013;31:1136-43.

17. Beckett NS, Peters R, Fletcher AE, et al. Treatment of hypertension in patients 80 years of age or older. N Engl J Med 2008;358:1887-98.
18. Conen D, Aeschbacher S, Thijs L, et al. Age-specific differences between conventional and ambulatory daytime blood pressure values. Hypertension 2014;64:1073-9.

19. Myers MG, Reeves RA. White coat effect in treated hypertensive patients: sex differences. J Hum Hypertens 1995;9:729-33.

20. Manios ED, Koroboki EA, Tsivgoulis GK, et al. Factors influencing white-coat effect. Am J Hypertens 2008;21: 153-8.

21. Stergiou GS, Salgami EV, Tzamouranis DG, et al. Masked hypertension assessed by ambulatory blood pressure versus home blood pressure monitoring: is it the same phenomenon? Am J Hypertens 2005;18:772-8.

22. Sega R, Trocino G, Lanzarotti A, et al. Alterations of cardiac structure in patients with isolated office, ambulatory, or home hypertension: data from the general population (Pressione Arteriose Monitorate E Loro Associazioni [PAMELA] Study). Circulation 2001;104:1385-92.

23. Imai Y, Tsuji I, Nagai K, et al. Ambulatory blood pressure monitoring in evaluating the prevalence of hypertension in adults in Ohasama, a rural Japanese community. Hypertens Res 1996;19:207-12.

24. Selenta C, Hogan BE, Linden W. How often do office blood pressure measurements fail to identify true hypertension? An exploration of white-coat normotension. Arch Fam Med 2000;9:533-40.

25. Bobrie G, Clerson P, Ménard J, et al. Masked hypertension: a systematic review. J Hypertens 2008;26:1715-25.

26. Pickering TG, Davidson K, Gerin W, et al. Masked hypertension. Hypertension 2002;40:795-6.

27. Wing LM, Brown MA, Beilin LJ, et al. Reverse whitecoat hypertension in older hypertensives. J Hypertens 2002;20:639-44.

28. O'Sullivan C, Duggan J, Atkins N, et al. Twenty-fourhour ambulatory blood pressure in community-dwelling elderly men and women, aged 60-102 years. J Hypertens 2003;21:1641-7.

29. Lurbe E, Torro I, Alvarez V, et al. Prevalence, persistence, and clinical significance of masked hypertension in youth. Hypertension 2005;45:493-8.

30. Alwan H, Pruijm M, Ponte B, et al. Epidemiology of masked and white-coat hypertension: the family-based SKIPOGH study. PLoS One 2014;9:e92522.

31. Trachsel LD, Carlen F, Brugger N, et al. Masked hypertension and cardiac remodeling in middle-aged endurance athletes. J Hypertens 2015;33:1276-83.

32. Grassi G, Turri C, Vailati S, et al. Muscle and skin sympathetic nerve traffic during the "white-coat" effect. Circulation 1999;100:222-5.

33. Folkow B. Physiology of behaviour and blood pressure regulation in animals. In: Julius $\mathrm{S}$, Bassett DR, eds. Handbook of hypertension, vol. 9: Behavioral factors in hypertension. Amsterdam: Elsevier Science Publishers; 1987. pp 1-18.

34. Kozlowski LT, Herman CP. The interaction of psychosocial and biological determinants of tobacco use: more on the boundary model. J Appl Soc Psych 1984;14:244-56.

35. Grassi G, Turri C, Vailati S, et al. Muscle and skin sympathetic nerve traffic during the "white-coat" effect. Circulation 1999;10:222-5.

36. Terracciano A, Scuteri A, Strait J, et al. Are personality traits associated with white-coat and masked hypertension? J Hypertens 2014;32:1987-92. 
37. Grassi G, Esler M. How to assess sympathetic activity in humans. J Hypertens 1999;17:719-34.

38. Ogedegbe G, Pickering TG, Clemow L, et al. The misdiagnosis of hypertension: the role of patient anxiety. Arch Intern Med 2008;168:2459-65.

39. Spruill TM, Pickering TG, Schwartz JE, et al. The impact of perceived hypertension status on anxiety and the white coat effect. Ann Behav Med 2007;34:1-9.

40. Grassi G. Assessment of sympathetic cardiovascular drive in human hypertension: achievements and perspectives. Hypertension 2009;54:690-7.

41. Mann SJ, James GD, Wang RS, et al. Elevation of ambulatory systolic blood pressure in hypertensive smokers. A case-control study. JAMA 1991;265:2226-8.

42. Bang LE, Buttenschøn L, Kristensen KS, Svendsen TL. Do we undertreat hypertensive smokers? A comparison between smoking and non-smoking hypertensives. Blood Press Monit 2000;5:271-274.

43. Ishikawa J, Kario K, Eguchi K, et al. Regular alcohol drinking is a determinant of masked morning hypertension detected by home blood pressure monitoring in medicated hypertensive patients with well-controlled clinic blood pressure: the Jichi Morning Hypertension Research (J-MORE) study. Hypertens Res 2006;29:679-86.

44. Leary AC, Donnan PT, MacDonald TM, et al. The influence of physical activity on the variability of ambulatory blood pressure. Am J Hypertens 2000;13:1067-73.

45. Pieper C, Warren K, Pickering TG. A comparison of ambulatory blood pressure and heart rate at home and work on work and non-work days. J Hypertens 1993;11:177-83.

46. Enström I, Pennert K. Does it matter whether ambulatory blood pressure is recorded during a work day or a non-work day? J Hypertens 1996;14:565-9.

47. Belkić KL, Schnall PL, Landsbergis PA, et al. Hypertension at the workplace - an occult disease? The need for work site surveillance. Adv Psychosom Med 2001; 22:116-38.

48. Aydin Y, Kaltenbach M. Noise perception, heart rate and blood pressure in relation to aircraft noise in the vicinity of the Frankfurt airport. Clin Res Cardiol 2007;96:347-58.

49. Lusardi P, Mugellini A, Preti P, et al. Effects of a restricted sleep regimen on ambulatory blood pressure monitoring in normotensive subjects. Am J Hypertens 1996;9:503-5.

50. Ben-Dov IZ, Ben-Ishay D, Mekler J, et al. Increased prevalence of masked blood pressure elevations in treated diabetic subjects. Arch Intern Med 2007;167:2139-42.

51. Jaques H. National Institute for Health and Clinical Excellence (NICE). NICE guideline on hypertension. Eur Heart J 2013;34:406-8.

52. Kuwajima I, Suzuki Y, Fujisawa A, et al. Is white coat hypertension innocent? Structure and function of the heart in the elderly. Hypertension 1993;22:826-31.

53. Glen SK, Elliot HL, Curzio JL, et al. White-coat hypertension as a cause of cardiovascular dysfunction. Lancet 1996;348:654-7.

54. Cuspidi C, Rescaldani M, Tadic M, et al. White-coat hypertension, as defined by ambulatory blood pressure monitoring, and subclinical cardiac organ damage: a meta-analysis. J Hypertens 2015;33:24-32.

55. Barnett PA, Spence JD, Manuck SB, et al. Psychological stress and the progression of carotid artery disease. J Hypertens 1997; 15:49-55.
56. Cuspidi C, Sala C, Tadic M, et al. Is white-coat hypertension a risk factor for carotid atherosclerosis? A review and meta-analysis. Blood Press Monit 2015;20: 57-63.

57. Hara A, Ohkubo T, Kikuya M, et al. Detection of carotid atherosclerosis in individuals with masked hypertension and white-coat hypertension by self-measured blood pressure at home: the Ohasama study. J Hypertens 2007;25:321-7.

58. Mancia G, Bombelli M, Facchetti R, et al. Long-term risk of sustained hypertension in white-coat or masked hypertension. Hypertension 2009;54:226-32.

59. Bombelli M, Facchetti R, Carugo S, et al. Left ventricular hypertrophy increases cardiovascular risk independently of in-office and out-of-office blood pressure values. J Hypertens 2009;27:2458-64.

60. Pierdomenico S, Lapenna D, Di Mascio R, Cuccurullo F. Short- and long-term risk of cardiovascular events in white-coat hypertension. J Hum Hypertens 2008;22: 408-14.

61. Hansen TW, Jeppesen J, Rasmussen S, et al. Ambulatory blood pressure monitoring and risk of cardiovascular disease: a population based study. Am J Hypertens 2006;19:243-50.

62. Kario K, Shimada K, Schwartz JE, et al. Silent and clinically overt stroke in older Japanese subjects with whitecoat and sustained hypertension. J Am Coll Cardiol 2001;38:238-45.

63. Fagard RH, Cornelissen VA. Incidence of cardiovascular events in white-coat, masked and sustained hypertension versus true normotension: a meta-analysis. J Hypertens 2007;25:2193-8.

64. Gustavsen PH, Høegholm A, Bang L, Kristensen KS. White coat hypertension is a cardiovascular risk factor: A 10-year follow-up study. J Hum Hypertens 2003;17: 811-7.

65. Mancia G, Bombelli M, Facchetti R, et al. Increased long-term risk of new-onset diabetes mellitus in whitecoat and masked hypertension. J Hypertens 2009;27: 1672-8.

66. Sega R, Facchetti R, Bombelli M, et al. Prognostic value of ambulatory and home blood pressures compared with office blood pressure in the general population: followup results from the Pressioni Arteriose Monitorate e Loro Associazioni (PAMELA) study. Circulation 2005; 111:1777-83.

67. Cuspidi C, Sala C, Tadic M, et al. Untreated masked hypertension and subclinical cardiac damage: a systematic review and meta-analysis. Am J Hypertens 2015;28: 806-13.

68. Manios E, Michas F, Stamatelopoulos K, et al. Association of isolated systolic, isolated diastolic, and systolicdiastolic masked hypertension with carotid artery intima-media thickness. J Clin Hypertens 2015;17:22-6.

69. Cuspidi C, Sala C, Tadic M, et al. Untreated masked hypertension and carotid atherosclerosis: a meta-analysis. Blood Press 2015;24:65-71.

70. Liu JE, Roman MJ, Pini R, et al. Cardiac and arterial target organ damage in adults with elevated ambulatory and normal office blood pressure. Ann Intern Med 1999; 131:564-72.

71. Fukuhara M, Arima H, Ninomiya T, et al. White-coat and masked hypertension are associated with carotid 
atherosclerosis in a general population: the Hisayama study. Stroke 2013;44:1512-7.

72. Björklund K, Lind L, Zethelius B, et al. Isolated ambulatory hypertension predicts cardiovascular morbidity in elderly men. Circulation 2003;107:1297-302.

73. Oe Y, Shimbo D, Ishikawa J, et al. Alterations in diastolic function in masked hypertension: findings from the masked hypertension study. Am J Hypertens 2013;26: 808-15.

74. Lurbe E, Thijs L, Torro MI, et al. Sexual dimorphism in the transition from masked to sustained hypertension in healthy youths. Hypertension 2013;62:410-4.

75. Hansen TW, Jeppesen J, Rasmussen S, et al. Ambulatory blood pressure monitoring and risk of cardiovascular disease: a population based study. Am J Hypertens 2006;19:243-50.

76. Shimbo D, Newman JD, Schwartz JE. Masked hypertension and prehypertension: diagnostic overlap and interrelationships with left ventricular mass: the Masked Hypertension Study. Am J Hypertens 2012;25:664-71.

77. Skårn SN, Flaa A, Kjeldsen SE, et al. High screening blood pressure at young age predicts future masked hypertension: a 17 year follow-up study. Blood Press 2015; 24:131-8.

78. Viera AJ, Lin FC, Tuttle LA, et al. Levels of office blood pressure and their operating characteristics for detecting masked hypertension based on ambulatory blood pressure monitoring. Am J Hypertens 2015;28:42-9.

79. Kario K, Hoshide S, Haimoto H, et al. Sleep blood pressure self-measured at home as a novel determinant of organ damage: Japan morning surge home blood pressure (J-HOP) study. J Clin Hypertens (Greenwich) 2015; 17:340-8

80. Banegas JR, Ruilope LM, de la Sierra A, et al. High prevalence of masked uncontrolled hypertension in people with treated hypertension. Eur Heart J 2014;35:3304-12.

81. Kanno A, Kikuya M, Asayama K, et al. Night-time blood pressure is associated with the development of chronic kidney disease in a general population: the Ohasama Study. J Hypertens 2013;31:2410-7.

82. Kario K, Hoshide S, Haimoto H, et al. Sleep blood pressure self-measured at home as a novel determinant of organ damage: Japan morning surge home blood pressure (J-HOP) study. J Clin Hypertens (Greenwich) 2015; $17: 340-8$

83. Kang YY, Li Y, Huang QF, et al. Accuracy of home versus ambulatory blood pressure monitoring in the diagnosis of white-coat and masked hypertension. J Hypertens 2015;33:1580-7.

84. Hänninen MR, Niiranen TJ, Puukka PJ, et al. Target organ damage and masked hypertension in the general population: the Finn-Home study. J Hypertens 2013; 31:1136-43.

85. Sivén S, Niiranen T, Kantola I, et al. White-coat and masked hypertension as risk factors for progression to sustained hypertension: the Finn-home study. J Hypertens 2015;33:e5-6.

86. Mancia G, Bombelli M, Serravalle G, Grassi G. Diagnosis and management of patients with white-coat and masked hypertension. Nat Rev Cardiol 2011;8:686-93.

87. Zanchetti A, Bond MG, Hennig M, et al. Calcium antagonist lacidipine slows down progression of asymptomatic carotid atherosclerosis: principal results of the European Lacidipine Study on Atherosclerosis (ELSA), a randomized, double-blind, long-term trial. Circulation 2002; 106:2422-7.

88. Franklin SS, Thijs L, Hansen TW, et al. Significance of white-coat hypertension in older persons with isolated systolic hypertension: a meta-analysis using the International Database on Ambulatory Blood Pressure Monitoring in Relation to Cardiovascular Outcomes population. Hypertension 2012;59:564-71.

89. Fagard RH, Staessen JA, Thijs L, et al. Response to antihypertensive therapy in older patients with sustained and nonsustained systolic hypertension. Systolic Hypertension in Europe (Syst-Eur) Trial Investigators. Circulation. 2000;102:1139-44.

90. Law MR, Morris JK, Wald NJ. Use of blood pressure lowering drugs in the prevention of cardiovascular disease: meta-analysis of 147 randomised trials in the context of expectations from prospective epidemiological studies. BMJ 2009;338:b1665.

91. Pierdomenico SD, Lapenna D, Bucci A, et al. Cardiovascular outcome in treated hypertensive patients with responder, masked, false resistant, and true resistant hypertension. Am J Hypertens 2005;18:1422-8.

92. Angeli F, Reboldi G, Verdecchia P. Masked hypertension: evaluation, prognosis, and treatment. Am J Hypertens 2010;23:941-8.

93. Ben-Dov IZ, Ben-Ishay D, Mekler J, et al. Increased prevalence of masked blood pressure elevations in treated diabetic subjects. Arch Intern Med 2007;167:2139-42.

94. Monteagudo PT, Nóbrega JC, Cezarini PR, et al. Altered blood pressure profile, autonomic neuropathy and nephropathy in insulin-dependent diabetic patients. Eur J Endocrinol 1996;135:683-8.

95. American Diabetes Association. Standards of medical care in diabetes 2014. Diabetes Care 2014;37:S14-80.

96. Franklin SS, Thijs L, Li Y, et al. Masked hypertension in diabetes mellitus: treatment implications for clinical practice. Hypertension 2013;61:964-71.

97. Asayama K, Sato A, Ohkubo T, et al. The association between masked hypertension and waist circumference as an obesity-related anthropometric index for metabolic syndrome: the Ohasama study. Hypertens Res 2009;32: 438-43.

98. Verdecchia P, Reboldi G, Porcellati C, et al. Risk of cardiovascular disease in relation to achieved office and ambulatory blood pressure control in treated hypertensive subjects. J Am Coll Cardiol 2002;39:878-85. 